\title{
Interactive comment on "Assessing the role of planetary and gravity waves on the vertical structure of ozone over central Europe" by Peter Križan
}

\section{Peter Krizan \\ krizan@ufa.cas.cz}

Received and published: 13 March 2019

Anonymous Referee \#2 Based on the Teitelbaum method, this manuscript studies the characteristics of ozone lamina under the inïnćuence of planetary and gravity waves. This article seems to have done a lot of work. Even though I'm not an expert in this area (ozone lamina), there are a few things that make me confused. Major comments: 1 The formation mechanism of ozone lamina. Tomikawa et al. (2002) reported that the formation of the ozone laminae is closely related to the vertical shear of the subtropical jet. I strongly suggest the authors to discuss in the introduction about the formation mechanisms of the ozone lamina and in which the role of wave activities play. Tomikawa, 
Y. , Sato, K. , Kita, K. , Fujiwara, M. , Yamamori, M. , \& Sano, T. . (2002). Formation of an ozone lamina due to differential advection revealed by intensive observations. J. Geophys. Res., 107(D10).

This paper is referred to in Discussion.

2. Lines 101-108, need some references (at least one) or make some explanation: e.g. Why choose $5-15 \mathrm{~km}$ and $17-22 \mathrm{~km}$ height area to distinguish. If the identiînAzcation process is proposed by the author, it appears from the description that the author only uses ozone thin layers at different height region to deïñ is caused by gravity or planetary waves. This makes it very puzzling because gravity waves almost exist anywhere in the earth's atmosphere.

I did the research for all heights from the ground to the $5 \mathrm{~km}$ below the highest profile point. The intervals $5-15 \mathrm{~km}$ and $17-22 \mathrm{~km}$ were chosen because the correlation here is sufficiently high (above 0.7 ) or low (below 0.3 ) for detection of gravity and planetary waves. In these intervals the ozone profile are strongly influenced by atmospheric waves. Outside these intervals the profile is not so strongly influenced as in these intervals. The atmospheric waves can occur outside intervals, but they do not influence the ozone vertical profile.

3. The authors have only mentioned the thin layer of ozone caused by gravitational and planetary waves, but I think that some other meso-and small-scale atmospheric processes (such as strong convection, tropopause folding, strong wind shear, stratospheric streamers, etc.) may also responsible for the formation of ozone laminae.

Various mechanisms of lamina formation is described in the Discussion

4. Gravity and planetary waves run through the title and the paper, but there is no evidence of their existence in the manuscript (even though the authors indicate that the ozone proïňĄle can be used to detect ïňĆuctuations)

Interactive

comment

This title of paper was recommended by editor.

Printer-friendly version

Discussion paper 
5. Reading the manuscript, I still didn't understand how gravity and planetary waves affect and lead to ozone laminae. Personally, a detailed case is necessary.

ANGEOD

This problem is theoretically solved in Teitelbaum paper.

Minor comments: 1 . Lines $44-46$, as you mentioned, it is the large lamina that has a close correlation with the total ozone content, not the narrow lamina. The actual signiïňAcance of narrow lamina still not clear throughout the manuscript.

We were interested in laminae of various sizes because according to theory gravitational waves produce predominantly small size laminae. On the other hand planetary waves are able to form also the large laminae.

2. Lines 47-48, needs relevant references (at least one),especially about the inïňĆuence of waves on the laminae.

The references were given in the Introduction. 3. Line 75 from->on ?

4. Line 76 for the approximating-> for approximating

This grammar mistakes were corrected

5. Line 125 partitioning of laminae-> partitioning laminae?

We can say partitioning of laminae or lamina partitioning but not partitioning laminae

6. Conclusion: as mentioned in the introduction, if the Teitelbaum method is suitable for central Europe? And how well?

Teitelbaum method was demonstrated for data at the Sodankyla (northern Finland) and this method was able to detect atmospheric waves in the ozone profile. Grant et al. (1998) used the same method for the tropical station $\backslash s$ and this method brought reasonable results. So we suppose this method is suitable also for the stations in Europe, because we obtained results which were expected in the case of well working method, 
Interactive comment on Ann. Geophys. Discuss., https://doi.org/10.5194/angeo-2018-123, 2018.
ANGEOD

Interactive

comment 